\title{
TWEE (?) DUITSE VLIEGTUIE VAN DUALA
}

\section{Inleiding}

In brig.-genl F. J. Moberly, C.B., C.S.I., D.S.O. se bekende werk Military Operations Togoland and the Cameroons 1914-1916, (London, 1931) is op p. 203 vermeld dat brig.-genl. E. H. Gorges op 11 Desember 1914 die Duitse pos Bare, noord van die eindpunt van die noordelike spoorlyn (Duala-Nkongsamba), beset het. Behalwe ongeveer 40 Duitsers, waaronder 'n paar vrouens en kinders, het 'n groot hoeveelheid voorrade en 2 vliegtuie in kaste in hande van hierdie Britse kolonne geval. Hierdie vliegtuie was, aldus die skrywer, die eerste wat in WesAfrika aangekom het.

Vermoedelik was dit dié vliegtuie waarvan die verdere lotgevalle in die lêer German Monoplanes from Duala, aanwesig onder die dokumente in die Militêr-Historiese en Argivale Dienste, Pretoria, meer besonderhede verstrek.

1 Die Unieregering aanvaar die aanbod. Dr. Weston se hulp ingeroep

Op 16 Desember 1914 stuur die Sekretaris van die Britse Departement van Kolonies 'n telegram aan die goewerneur-generaal te Pretoria met die versoek om vas te stel of 'n tweetal Duitse vliegtuie, wat in die Duitse Kameroen buitgemaak is en veronderstel is om in 'n goeie toestand te verkeer, van nut vir die Unieregering sal wees.

Indien die vliegtuie begeer word, kan die sekretaris en luitenant-generaal C. M. Dobell, inspekteur-generaal van die West African Frontier Force en bevelhebber van die Brits-Franse taakmag in die Kameroen, regstreeks ingelig word. Die vliegtuie kan dan met 'n prysskip, wat deur die Unieregering gebruik kan word, van Duala na Suid-Afrika gestuur word.

Op 17 Desember 1914 antwoord genl. Louis Botha dat sy regering die aanbod met graagte sal aanvaar en drie dae later telegrafeer luitenant-generaal Dobell na Londen dat die datum van aankoms van die vliegtuie op Duala sal afhang van die tyd wat nodig sal wees om 'n spoorbrug te herstel. Dit sal, op die vroegste, teen die einde van Desember die geval wees.

Terwyl luitenant-generaal Dobell belowe om die datum van vertrek van die prysskip en die aankomsdatum (Kaapstad) te stuur, berig hy verder dat die vliegtuie nie inmekaar gesit is nie en dat dit moeilik is om te sê of hulle volledig is.

Op 23 Desember 1914 antwoord die Unie se Eerste Minister dat hy hoop dat die vertrek van die twee prysskepe nie as gevolg van die oponthoud van die aankoms van die vliegtuie vertraag sal word nie en dat dit van die allerhoogste belang is dat hulle ten spoedigste in Kaapstad aankom.

Hierop is geantwoord dat die Edna Woermann nie gereed sal wees voordat die vliegtuie aan die kus sal aankom nie.

Uit ander bronne blyk dat die Unieregering die vliegtuie met betrekking tot die veldtog in Duits Suidwes-Afrika wou besit en dat dit feitlik as vanselfsprekend beskou is om hulle, na aankoms in Kaapstad, in gereedheid te bring.

Ruim twee weke voordat die skip met sy kosbare lading in Kaapstad aangekom het, het die Sekretaris van Verdediging dan ook die hulp van die bekende vliegtuigonderwerper- vervaardiger dr. John L. Weston, F.R.G.S., A.I.E.E., van Brandfort, ingeroep om "herstelwerk” aan die twee Taube-vliegtuie te verrig. Op 11 Januarie 1915 antwoord Weston dat hy voorstel dat die benodigde materiaal m.b.t. herstelwerk sonder versuim bestel word en hy voeg hieraan toe: 
In order to minimise the Engine troubles which will be caused by the sand of German S.W.A. each machine lent by the Imperial Govt. should be supplied with a sand-proof cover to fit over and protect the Engine while the machine is not in actual use.

As it is practically certain that amongst the German Aero Engines in the possession of the Imperial Govt. some are damaged and useless to them it would be well to obtain a list of all the serviceable parts they could send us, should we require any for the repairs to the Taube's Engines.

Aan hierdie raadgewings voeg dr. Weston, wat homself op sy briefhoofde beskrywe as „Member of the Aeronautical Society of Gt. Britain. Pilot Aviator of the Aero Clubs of France and Britain. Airship pilot and Aeronaut of the International Aeronautical Federation. Consulting Aeronautical Engineer," toe dat hy in Londen 'n nuwe Gnome-enjin van 80 pk., met gereedskap en onderdele, 'n feitlik nuwe Gnome-enjin van $50 \mathrm{pk}$. sonder oliepomp, 'n nuwe Bleriot-skroef vir 'n eenpersoons-vlieg'uig van 50 pk., 'n nuwe Chouvière-skroef en 'n Chenard Walker-enjin van 16 tot $20 \mathrm{pk}$. het.

Op 14 Januarie 1915 het sekretaris Bourne aan dr. Weston meegedeel dat hy die skip teen die einde van die maand verwag en dat hy reken dat, tot tyd en wyl die bruikbaar- of onbruikbaarheid van die vliegtuie vasgestel kan word, dit nie van nut sal wees om onderdele te bestel nie. Wanneer die vlieëniers van Engeland sou terugkeer, dan sou - aldus sekretaris Bourne - die vraag oorweeg kan word of die vliegtuie vir reserwe-doeleindes in Suidwes gebruik kan word.

Op 2 Februarie 1915 het dr. Weston amptelik berig ontvang dat die Edna Woermann in Kaapstad aangekom het en dat hy versoek word om soontoe te gaan en na aankoms aldaar met kapt. H. B. Tumer, van die Z.A.V.K., by die Kasteel in verbinding moet tree om reëlings te tref om die vliegtuie op te knap en in dié verband te rapporteer.

Aangaande die toestand waarin die vliegtuie ten tye van die inname van Bare verkeer het, het. It.-genl. C. M. Dobell op 18 Januarie 1914 aan die goewerneur-generaal meegedeel dat die kaste gedecltelik uitgepak en een van die verkoelers verniel was. Skroewe en dele van die verkoelers wat los aangetref is, is in die poskajuit van die Edna Woermann geplaas. 'n Vyftal afdrukke, waarvan dit onmoontlik is om vas te stel of hulle betrekking op die vliegtuie het, is in die kajuit van die hoofmasjinis van die stoomskip Henrietta Woermann gevind en deur die generaal aangestuur, terwyl daar by hierdie moontlike dokumentasie ook 'n verklaring gevoeg is wat, m.b.t. die vliegtuie en die verpakking, deur kapt. C. Fuller, R.N., opgestel is.

Nog 'n teenslag wat die nuwe besitters van die vliegtuie getref het, was die feit dat sekere aanduidings op die kaste gedeeltelik uitgevee was waardeur dit onmoontlik was om vas te stel of die twee vliegtuie volledig was of nie.

In kapt. Fuller se verslag is, op grond van gegewens soos deur 'n sekere Davidson, van Militêre Inligting verstrek is, vermeld dat die 2 vliegtuie op 11 Januarie deur 'n lugvaartkundige vereniging in Duitsland per skip van Hamburg na die Kameroen gestuur is met die bedoeling om hulle oor die Benurivier na Garua te neem. Daar sou 'n groep vlieëniers hulle gebruik om proefnemings naby die Chad-meer te neem.

Altesame 15 kaste, waarvan die 3 grootstes N.B.G.T. 16, Warri, Nigeria gemerk was, is aan boord van die skip geplaas. Tewens is die volgende opskrif op die reeds genoemde kaste aangetref: Regierungsgut für Guara Flug Exp. Twee 
kleiner kaste was onderskeidelik N.B.T.G. 7 Warri en N.B.T.G. 49 304/1 Warri gemerk terwyl uit die verskepingsdokumente afgelei kon word dat alles deur die firma Matthias Rode en Kie. met die stoomskip Renate Amsinck versend is.

Die volgende was bestemd vir Niger Benue Gest : M.C.H. Imperial Resident, Garua : N.B.T.G. 16/1 (een kas) - met vliegtuigapparate; 17/8 (twee kaste) - met vliegtuie, 20 (een kas) - met skroef, 7 (een krat of drie kaste) - met staaldraadkabel, 49304 (kaste nos. 1-4) - met landboumasjinerie, 49304 (kaste nos. 5-8) - met landboumasjinerie.

Ongelukkig is die skeepsjoernaal van die Renate Amsinck' nie aangetref nie, terwyl die skip nòg Warri nòg Forcados aangedoen het nie. Op grond hiervan het Donaldson tot die gevolgtrekking gekom dat die Duitse owerhede die vliegtuie te Duala opgekommandeer het.

\section{Dr. Weston se bevindings}

Op 12 Februarie 1915 is van Kaapstad van die Departement van Verdediging berig dat al die kaste van die Edna Woermann afgelaai is en dat die vliegtuie in die Kaapstadse drilsaal inmekaar gesit word.

Twee dae later stel dr. Westor voor dat, wanneer die Taube-vliegtuie herstel sal wees, hulle as buitgemaakte vliegtuie aan die publiek ter stywing van oorlogsfondse vertoon word. Op dié wyse kan daar volgens hom 'n groot bedrag ingesamel word.

Sekretaris Bourne kon hom nie met dié gedagte vereenselwig nie en dr. Weston het met sy werksaamhede voortgegaan en op 19 Maart 'n lys van onderdele captured in the Cameroon with two "Jeannin" monoplanes, na Pretoria gestuur.

Hierdie lys, wat op 8 Maart 1915 deur die Zuid-Afrikaansche Vliegenierskorps (Z.A.V.K.) opgestel is, word interessantheidshalwe volledig weergegee ten einde die belangstellende leser 'n oorsig te verstrek van alles wat i.v.m. die bou en onderhoud van 'n toenmalige vliegtuig as nodig beskou is.

INVENTORY OF STORES RELATING TO TWO JEANNIN MONOPLANES

METAL WORKING MATERIAL:

No. of

Articles

Description of Articles

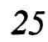

50

48

49

48

48

\section{Length Diameter m.m. m.m.}

$60.00 \quad 6.0$


No. of
Articles

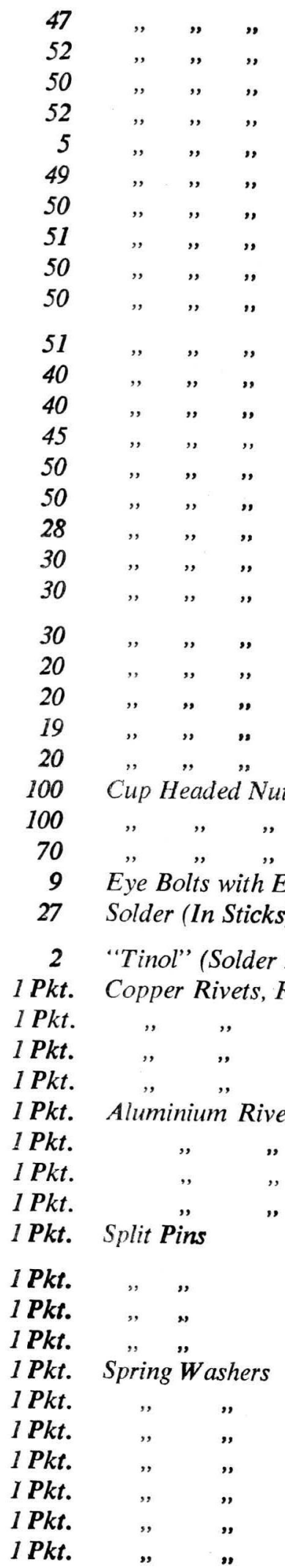

Length Diameter m.m. m.m.

$50.00 \quad 6.0$

$35.00 \quad 6.0$

$85.00 \quad 6.0$

$70.00 \quad 6.1$

$43.00 \quad 6.6$

$36.00 \quad 6.9$

$61.25 \quad 6.9$

$26.50 \quad 7.0$

$91.00 \quad 7.0$

$70.00 \quad 7.0$

$51.00 \quad 7.1$

$31.00 \quad 7.8$

$40.00 \quad 7.8$

$50.00 \quad 8.0$

$71.00 \quad 8.0$

$86.00 \quad 8.0$

$71.00 \quad 9.0$

$91.00 \quad 9.9$

$52.00 \quad 10.0$

$47.00 \quad 10.3$

$47.00 \quad 11.9$

$160.00 \quad 11.7$

$91.00 \quad 11.9$

$71.00 \quad 12.6$

$26.25 \quad 5.0$

$31.75 \quad 6.0$

$20.00 \quad 6.0$

$71.00 \quad 6.0$

$1^{\prime} 6^{\prime \prime}$

2.7

2.8

3.2

3.8

2.4

2.7

3.2

3.7

35

1.0

$\begin{array}{ll}40 & 1.7\end{array}$

$30 \quad 2.0$

$33 \quad 3.0$

4.0

6.0

5.0

7.0

8.0

10.0

12.0 
METAL WORKING TOOLS:

No. of Articles

Description of Articles

Length WidthThicknessDiameter m.m. m.m. m.m. m.m.

1 Saw File

$1 \quad \frac{3}{8}$ Square File

2 Rat Tailed Files

$$
\begin{aligned}
& \text { 4" } \\
& 7^{\prime \prime} \quad \frac{3 "}{8} \quad \frac{3}{8} \\
& 1 \text { " " }, 10 "
\end{aligned}
$$$$
3 \text { " " " } 9
$$

1 Rat Tailed Smooth File $I^{\prime} 0^{\prime \prime}$

2 " , " , $1^{\prime} 0^{\prime \prime}$

$2 \quad, \quad, \quad, \quad, \quad I^{r} \frac{1}{2}{ }^{\prime \prime}$

$1 \quad, \quad, \quad, \quad$ " $11^{\prime} 3^{\prime \prime}$

2 Half Round Bastard File 7"

$\begin{array}{llll}1 & , & , & ,\end{array}$

2 Flat Bastard Files

, 8"

, 9"

" $1^{\prime} 0^{\prime \prime}$

$9^{\prime \prime} \quad 1^{\prime \prime}$

2 , " ,

3 Flat Smooth Files

2 Steel Square

$11^{\prime \prime} 11^{\prime \prime}$

$I^{\prime} 0^{\prime \prime} \quad 11^{\prime \prime} \quad 5 / 16^{\prime \prime}$

$I^{\prime} 1^{\prime \prime} \quad 1^{\prime} \mathbf{3}^{\prime \prime} \quad \frac{5^{\prime \prime}}{8}$

4 Prs. Wire Benders

3' $0^{\prime \prime}$

$1^{\prime \prime}$
$\frac{3}{8}{ }^{\prime \prime}$
$\frac{3^{\prime \prime}}{8}$
$\frac{1^{\prime \prime}}{2}$
$\frac{5}{8}{ }^{\prime \prime}$
$\frac{1}{2}{ }^{\prime \prime}$
$3^{\prime \prime}$

2 Prs. Wire Benders

3 Prs. Wire Nippers

1 Pr. Wire Cutters

I' $1 \frac{1}{2}$

1 Pr. Shears

I' 3"

$7^{\prime \prime}$

2 Prs. Tongs

$1^{\prime} 0^{n}$

1 Pipe Wrench

$1^{\prime} 8^{\prime \prime}$

3 Worse Twist Drills

$1^{\prime} 9^{\prime \prime}$

m.m.

2.5

3.0

3.5

12 " , " , "

4.1

10 , , ,

$10 \quad ", "$,

12 , , ,

11 , , "

12 , , "

12 , , "

12 , " ,

$12, ", "$

8 " , ,

10.0

6 , " ,

$6, ", "$,

6 , ",

Half Vice (Incomplete)

1 (1 ft. encased) Grind Stone

1 Stilson Wrench

1 Screw Driver

2 Steel Chisels

1 Pr. Pr. Dividers 
No. of

Articles

$\begin{array}{rl}1 & \text { Spanner (Double End) } \\ 19 & \text { File Handles } \\ 1 & 1 \frac{1}{2} \text { Lb. Hammer and Handle } \\ 2 & 6 \text { Lb. Hammers and Handles } \\ 1 & \text { Braising Lamp } \\ 1 & \text { Splicing Tool }\end{array}$

OXY-ACETYLENE WELDING PLANT (PORTABLE):

No. of

Articles Description of Articles

1 Oxygen Tank

1 Acetylene Generator with Scrubber

2 Oxygen Cylinders

1 Blowpipe

4 Drums Carbide

24 Ft. Blowpipe Jets

2 Rubber Tubing

1 Tin Aluminium Flux

WOOD-WORKING TOOLS:

\begin{tabular}{|c|c|c|}
\hline $\begin{array}{l}\text { No. of } \\
\text { Articles }\end{array}$ & $\because$ & $\begin{array}{l}\text { Width } \\
\text { m.m. }\end{array}$ \\
\hline 1 & Chisel & $\frac{1}{2}$ \\
\hline 1 & ", & $\begin{array}{l}2 \\
\frac{1}{2}^{\prime \prime}\end{array}$ \\
\hline 1 & , & $\begin{array}{l}2 \\
\mathbf{3} " \prime\end{array}$ \\
\hline 1 & Twist Brace & \\
\hline 10 & Twist Brace Bits. Nos. 6, 8 , & $13,16,20,22,26,28$ \\
\hline 1 & 1 Ft. Square (Wood) & $10,10,20,22,20,20$ \\
\hline 1 & Claw Hammer & \\
\hline 1 & Claw Bar & $1^{\prime} 6^{\prime \prime}$ \\
\hline 1 & Distance Marker Guage & \\
\hline 1 & Pair Pincers & \\
\hline 3 & Cramps (Wooden) & \\
\hline 2 & (Bow) Saws & $l^{\prime} 9^{\prime \prime}$ \\
\hline 1 & Half Round Rasp & $6 \frac{1}{2} "$ \\
\hline 1 & Rat Tailed Rasp & $9 \frac{11 "}{2}$ \\
\hline 3 & Planes (Surfacing) No. 46 & \\
\hline 1 & Planes (Surfacing) No. 42 & \\
\hline 1 & Planes (Surfacing) No. 30 & \\
\hline 1 & 24" Ger. Measure (Wooden) & \\
\hline
\end{tabular}




\section{WOOD-WORKING MATERIAL:}

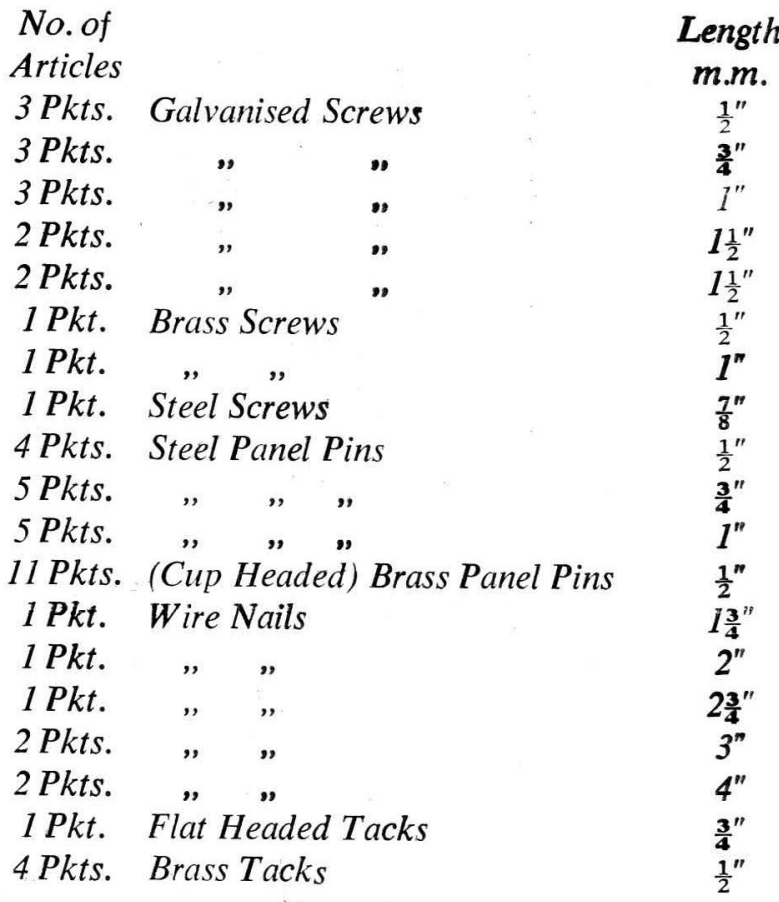

AEROPLANE EQUIPMENT:

\begin{tabular}{|c|c|c|c|}
\hline $\begin{array}{l}\text { No. of } \\
\text { Articles }\end{array}$ & Description of Articles & & Thickness Diameter \\
\hline 5 & Pulleys, Encased & & 50 m.m. \\
\hline 2 & , Uncased & & $50 \mathrm{~m} \cdot \mathrm{m}$ \\
\hline 5 & Encased & & 30 m.m. \\
\hline 11 & Uncased & & $20 \mathrm{~m} . \mathrm{m}$ \\
\hline 100 & Wire Fasteners & & $5 \mathrm{~m} . \mathrm{m}$. \\
\hline 200 & " Ferrules & & $2 m . m$. \\
\hline 300 & , & & $3 m . m$. \\
\hline 84 & $"$ & & 1 m.m. \\
\hline 10 & Pkts. Brass lace Eyelets & & $\frac{3}{8} "$ \\
\hline 1 & Brass Tyre Pump with Gauge & & \\
\hline 1 & $\begin{array}{l}\text { Wrought Iron Tyre Pump. } \\
\text { No Gauge. }\end{array}$ & & \\
\hline 1 & Roll Adhesive White Tape. & $11^{\prime \prime}$ & \\
\hline 5 & Rolls Canvas Binding Tape & $\frac{3}{4}^{\prime \prime}$ & \\
\hline 40 & Thimbles, Tinned & & $\frac{1}{8}^{\prime \prime}$ \\
\hline 40 & Do. & & $3 / 16^{\prime \prime}$ \\
\hline 44 & Do. & & $5 / 32^{\prime \prime}$ \\
\hline 50 & Do. & & $\frac{11 "}{4}$ \\
\hline 58 & Turn Buckles. Wire Strainers & & $3.2 \mathrm{~m} . \mathrm{m}$ \\
\hline 51 & Do. & & $3.6 \mathrm{~m} . \mathrm{m}$. \\
\hline 53 & Do. & & $4.2 \mathrm{~m} . \mathrm{m}$ \\
\hline 24 & Do. & & 4.9 m.m. \\
\hline 30 & Do. & & $6.5 \mathrm{~m} . \mathrm{m}$ \\
\hline 10 & Forked Turn Buckles & & $6.5 \mathrm{~m} . \mathrm{m}$ \\
\hline 1 & Oil Injector, Hand & & \\
\hline 4 & Clip Bolts, with Nuts & & \\
\hline 2 & Main Planes. (Unfit for Use) & & \\
\hline
\end{tabular}




$\begin{array}{ccc}1 & \text { Length Steel Round Tubing } \\ 1 & " \quad \text { Do. } \\ 1 & " \quad \text { Steel Oval Tubing } \\ 1 & " \quad \text { Do. } \\ 1 & \text { Steel Stream Line Tubes } \\ \text { (See attached diagram) } \\ 1 & \text { Steel Tubing, Oval, for landing } \\ & \text { chassis (See attached dia- } \\ & \text { gram } \quad \text { Do. } \\ 1 & \text { Bamboo Sticks, for Jeannin Tail }\end{array}$

\begin{tabular}{|c|c|c|}
\hline $\begin{array}{l}3^{\prime} 7^{\prime \prime} \\
3^{\prime} 6^{\prime \prime}\end{array}$ & $1 \mathrm{~m} . \mathrm{m}$. & $\begin{array}{c}63 \text { m.m. Int. } x \\
65 \text { m.m. Ext }\end{array}$ \\
\hline $18^{\prime}$ & $1 \mathrm{~m} . \mathrm{m}$. & \\
\hline $16^{\prime} 3^{\prime \prime}$ & $1 \mathrm{~m} . \mathrm{m}$. & $\begin{array}{l}17 \text { m.m. Major } x \\
10.5 \text { m.m. Minor }\end{array}$ \\
\hline $15^{\prime} 3^{\prime \prime}$ & $\begin{array}{l}1 \mathrm{~m} . \mathrm{m} . \\
1.5 \mathrm{~m} . \mathrm{m}\end{array}$ & $\begin{array}{c}60 \text { m.m.x } \\
34 \text { m.m. }\end{array}$ \\
\hline $15^{\prime} 6^{\prime \prime}$ & $1 \mathrm{~m} . \mathrm{m}$. & 90 m.m. $x$ \\
\hline $\begin{array}{c}15^{\prime} \\
\text { App. } \\
8^{\prime} 6^{\prime \prime}\end{array}$ & $1 \mathrm{~m} . \mathrm{m}$. & $\begin{array}{c}28 \text { m.m. } \\
\text { Approx. } \\
\mathbf{3}^{\prime \prime}\end{array}$ \\
\hline
\end{tabular}

ENGINE EQUIPMENT. MECHANICAL:

No. of

Articles

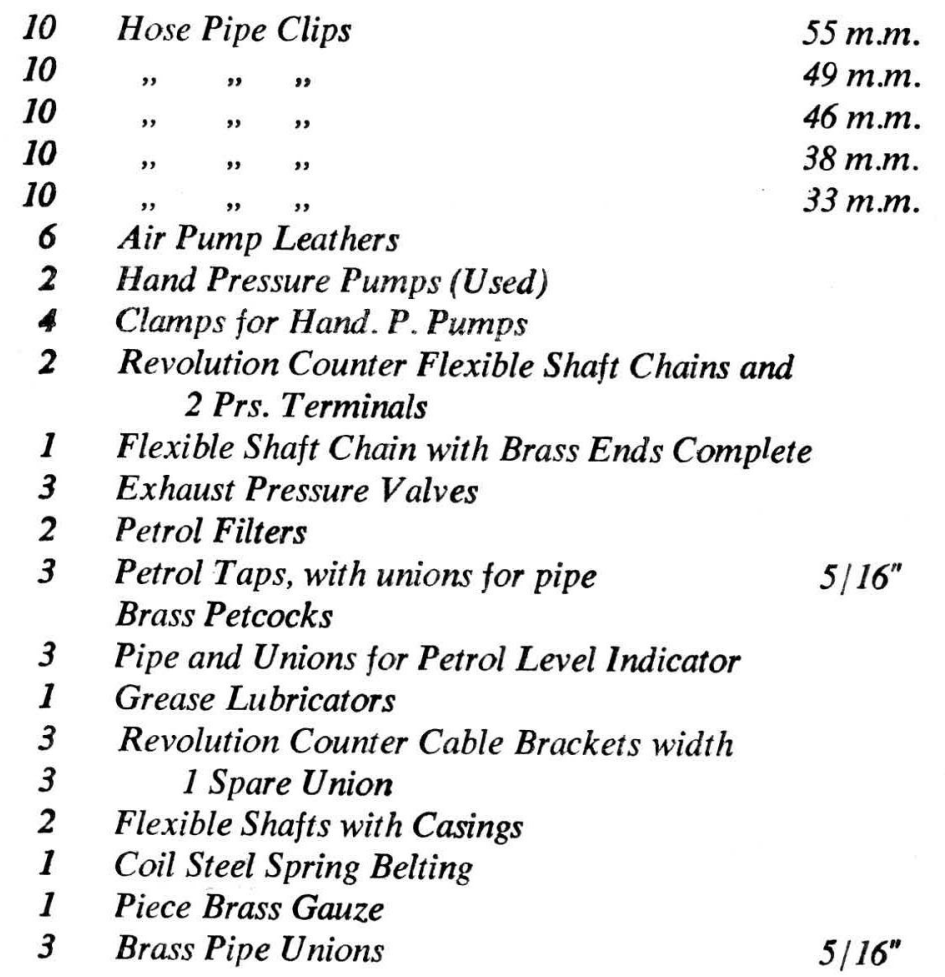

No. of

Articles

16 Cylinder Bosch Magneto, having no Distributor Connection. No. 1887867. Type Z.H.6.

16 Cylinder Bosch Magneto, with Distributor Connection and Spare Key. No. 1887859. Type Z.R.6.

2 Boxes Bosch Magneto Spares. Type Z.H.P.

1 Parcel containing 19 Bosch Sparking Plugs.

Diam $18 \mathrm{m.m}$. 
$1 \quad$ Parcel containig 33 Bosch Sparking Plugs.

Diam. 12 m.m.

18 Rolls Insulating Tape. Width $\frac{5 "}{8}$

$1 \quad$ Parcel containing High and Low Tension Wire loddments)

13 Way Switch.

\section{ENGINE EQUIPMENT AND SPARES FOR}

120 H.P. ARGUS ENGINE:

1 Connection Rod with Bearings and Gudgeon.

4 Bearings for Connecting Rods in Halves (8)

6 Exhaust Valves

8 Piston Rings

2 Pistons Complete with Gudgeon Pins and Bushes

8 Aluminium Elbows

24 Rubber Union Joints (Damaged)

2 Mercedes Radiators

1 Locking Cap for Propellor Boss

2 Sets Plug Wires and Casings

$1 \quad$ Piece Rubber Hose Pipe

1 , " , "

$1 \quad, \quad, \quad, \quad$,

1 Box containing odd Nuts, Bolts, etc.

ENGINE EQUIPMENT AND SPARES FOR

UNKNOWN ENGINE:

2 Pistons Complete with Rings and Gudgeon Pins

1 Key for Tractor $\mathrm{Hub}$

1 Brass Lubricator, Wick Type

3 Rockers

5 Exhaust Valves

1 Connecting Rod with Bearings and Gudgeon Pin Bush

2 Gudgeon Pins

4 Sets Big End Bearings

2 Big End Bolts

2 Copper Induction Pipes

1 Cam Shaft and Valve Gear

1 Carburettor with 1 Spare Needle and 2 Jets

$1 \quad$ Light Feed Oil Pump

2 Compression Tape

1 Drain Cock (Water Pump)

1 Radiator

\section{SPARE EQUIPMENT FOR}

“JEANNIN" MACHINE No. 1:

2 Wire Wheels Complete with Hubs. Landing Chassis

1 Wire Wheel, Rim only Landing Chassis

2 Spring Compression Struts Landing Chassis

2 Axle Valves (For Divided Axle Landing Chassis

4 Distance Cables, finished with

$$
\text { thimbles. Length 19" }
$$




\section{SPARE EQUIPMENT FOR}

"JEANNIN" MACHINE No. 2:

No. of

Articles

4 Main Struts

2 Terminal Bends

Wire Wheels complete with $\mathrm{Hubs}$

Wire Wheel, Rim only

Landing Chassis

Landing Chassis

Axle complete with Caps

Landing Chassis

Landing Chassis

Inner Tube, $560 \times 90$, old

Landing Chassis

7 Inner Tubes for Tyres, $660 \times 100$, old

$4 \quad$ Name Plates, Enamelled

1 Petrol Tank, Float Cover

3 Petrol Tank Caps

1 Coil Rubber Cable for Undercarriage

8 Tyre Covers. $660 \times 100$

WIRES AND CABLES. STOCK IN USE:

4 Coils Steel Wire

1 Coils Steel Wire

3 Coils Cable (Stranded)

3 Coils Cable (Stranded)

2 Coils Cable (Stranded)

3 Coils Charcoal Wire (Welding)

10 Gauge

12 Gauge

$\frac{1}{4}$ " Gauge

$3 / 16^{\prime \prime}$

$\frac{1}{8}$

PROPELLORS FOR 100 H.P. "JEANNIN" MONOPLANE

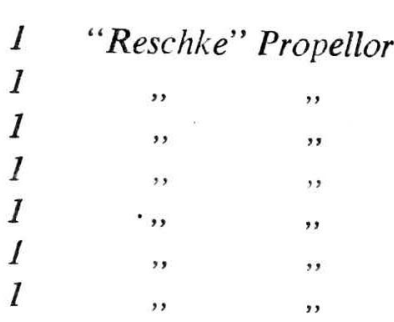

Diameter Pitch

26.50 m.m. $\quad 15.80$ m.m. No. 578

26.50 m.m. $\quad 15.80$ m.m. No. 620

26.80 m.m. $\quad 15.40$ m.m. No. 532

26.80 m.m. $\quad 15.40$ m.m. No. 588

27.00 m.m. $\quad 15.80$ m.m. No. 679

27.00 m.m. $\quad 14.80$ m.m. No. 666

25.60 m.m. $\quad 17.00$ m.m. No. 665

DOPES, VARNISHES AND PAINTS. APPROXIMATE

QUANTITIES. STOCK IN USE:

3 Tins Varnish

1 Tin Extra nurable Varnish

1 Stone Jar Anti-Rust Varnish

1 Glass Bottle Sulphuric Acid

7 Tins Dope

1 Tin Rubber Solution

1 Tin Turpentine

1 Tin Acetone

2 Tins Grease

$\begin{array}{rrr}\text { Gals. } & \text { Qts. } & P \text { ts. } \\ \text { Lbs. } & 2 & 0 \\ 1 & 2 & 0 \\ 0 & 2 & 0 \\ 0 & 1 & 1 \\ 20 & & \\ 2 & & \\ 1 & & \\ 2 & & \\ 18 & & \end{array}$


No. of

Articles

PAINTER'S TOOLS:

2 Brushes (Flat)

2 Brushes (Flat)

$1 \quad$ Brush, Round

$2 \quad$ Brushes, Round

2 Brushes, Round

1 Brushes, Round

1 Brushes, Round

$1 \quad$ Brushes, Round

1 Hand Sweeping Brush

1 Coil of Rope

4 Fire Extinguishers

1 Roll Damaged Fabric

1 Pair Climbing Irons

3 Sheets Alumininm each

2 Sheets Tin each

1 Sheet Wrought Iron

I

1

3 Tins Chalk Lime

$1 \quad$ Tin Coarse Emery

1 Tin Fine Emery

1 Tin French Chalk

1 Tin Engine Oil

6 Wooden Poles for Tent

2 ", " ,

$1 \quad, \quad, \quad$,

2 " " " "

12 Wooden Pegs for Tent

2 Sets Block and Tackle

Coil Rope

Iron Foot Plates

12 Base Pole Blocks (Wooden)

2 Iron Poles for Tent

\section{Length}

m.m.

Width Thichness

m.m.

m.m.

\section{$\frac{1}{2}^{\prime \prime}$ \\ $I^{\prime \prime}$}

No. 2

No. 4

No. 10

No. 12

No. 3

No. 6
6' 7"

$I^{\prime} 9^{\prime \prime}$

$3^{\prime} 0^{\prime \prime}$

$3^{\prime} 3^{\prime \prime}$

6' 7"

2' $6 "$

1' 9"

Lbs.

12

3

3

$\frac{1}{4}$

$Q t s$.

$13^{\prime} 6^{\prime \prime}$

$11^{\prime} 6^{\prime \prime}$

$9^{\prime} 0^{\prime \prime}$

6' 6"

2' 0 "

$136^{\prime \prime}$

$\left.8^{\prime}\right)^{\prime \prime}$

7'0"
1 m.m.

5 m.m.

1 m.m.

1 m.m.

1 m.m.

1 m.m.

1 m.m.

$4^{\prime} 3^{\prime \prime}$

I' 8 "

1' 8 "

$4 \frac{1}{4} \times 3^{\prime \prime}$

\section{Diameter}




\section{Verdere lotgevalle van die vliegtuie}

Tussen Maart 1915 en Januarie 1919 is daar, aldus in die betrokke lêer, geen besonderhede oor die twee vliegtuie aanwesig nie. Op laasgenoemde dag het 1t.-kol. G. Hodgson, waarnemende Distrik Stafoffisier, no. 1 Militêre Distrik, van Kaapstad 'n skrywe aan die Sekretaris van Verdediging gerig waarin my meegedeel het dat daar in die plaaslike drilsaal een of twee kaste staan wat, volgens hom, geruime tyd gelede deur die Z.A.V.K. agtergelaat is en onderdele van 'n Duitse vliegtuig of vliegtuie bevat. Reëlings is getref dat lt. A. H. Gearing, R.A.F., die kaste en die inhoud oorneem.

Op 11 Februarie 1919 het kol. T. Fowle, van die Imperiale troepe, die Kasteel, Kaapstad, aan die Sekretaris van Verdediging gerapporteer dat die Taube, wat vir uitstallingsdoeleindes geleen is, weer na die drilsaal teruggebring sal word.

Op dieselfde dag het die goewerneur aan die Unieregering laat verstaan dat die twee vliegtuie as oorlogstrofeë beskou en aan die Kaapstadse museum of enige ander gepaste instelling oorgedra kan word. Namens die Minister van Verdediging is die kurator van die genoemde museum op 17 Februarie 1919 dan ook met die aanbod in kennis gestel.

Intussen is op 13 Februarie 1919 toestemming verleen dat die Taube-vlieg tuig van 26-29 Maart vir uitstaldoeliendes deur die S.A. Railways and Harbours Big Push op Soutrivier op die plaaslike skouterrein deur 'n R.A.F.-offisier (vermoedelik 1t. Gearing) opgestel kan word. Op dié tydstip was die vliegtiug onder beheer van die stafoffisier, Kaapstad, en in die reeds genoemde drilsaal gehuisves.

Op 22 Februarie 1919 het die direkteur van die Transvaalse museum, Pretoria, die aanbod aanvaar om een van die vliegtuie te bekom. Reëlings m.b.t. die oordrag is met die Kwartiermeester-generaal getref, maar op 6 Maart 1919 het die waarnemende Sekretaris van Verdediging aan die direkteur van hierdie museum (dr. H. G. Breijer) meegedeel dat van die vliegtuig slegs die romp en vlerk aanwesig is. Op grond hiervan het die museum-komitee besluit om die aanbod nie te aanvaar nie.

Die direkteur van die Kaapstadse museum (dr. L. Peringue) het die aanbod op 25 Februarie weliswaar aanvaar, maar verklaar dat daar geen plek in die museum is nie. Op grond hiervan beveel hy aan dat die vliegtuig na die Big Pushfeestelikhede ten bate van die Goewerneur-generaalsfonds op Soutrivier, weer afgebreek en bewaar word tot tyd en wyl daar plek in die museum sal wees.

In 'n skrywe van 10 Maart 1919 het die Sekretaris van Verdediging aan die Big Push-komitee (Soutrivier) meegedeel dat die vliegtuig nou in besit van die Kaapstadse museum is en dat dit daar uitgestal sal word.

Ses dae vroeër het lt. Gearing, in opdrag van it.-kil. Hodgson, die inhoud van die kaste in die Kaapstadse drilsaal nagegaan en verklaar dat daar nie eers een volledige vliegtuig aanwesig is nie, maar wel voldoende onderdele om 'n vliegtuig vir museum-doeleindes te bou. Verder het hy nog 'n romp en 'n vlerk van 'n ander vliegtuig aangetref en bevind dat die materiaal verniel is.

Of die gerekonstrueerde Taube op Soùtrivier uitgestal is, blyk nie uit die beskikbare korrespondensie nie, ofskoon die voorsitter van die tentoonstellingkomitee op 7 Maart 1919 verklaar het dat die Taube op 10 Maart 1919 in ontvangs geneem sal word.

Op 17 Maart 1919 het die waarnemende Sekretaris van Verdediging aan die Sekretaris van Binnelandse Sake geskrywe dat daar aanvanklik die gedagte bestaan het dat twee volledige vliegtuie gestuur sou word. Nadat alles uitgepak 
was, is een volledige vliegtuig en van die ander slegs 'n romp en 'n vlerk gevind. Die vliegtuie was gestuur met die gedagte dat hulle deur die Unieregering gebruik kan word, maar so eindig die laaste brief oor die twee Duitse eendekkers van Duala, They were, however found to be useless.

Aan hierdie bevinding kan nog toegevoeg word dat daar hoogstens $1 \frac{1}{2}$ vliegtuie van Duala ontvang is en dat die Kaapstadse Suid-Afrikaanse museum vandag nie oor die Taube-vliegtuig beskik nie'2.

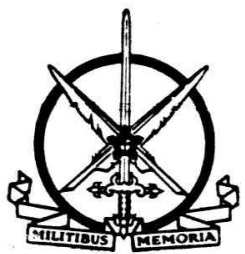




\section{SUMMARY}

A remarkable link between the Union of South Africa and the former Germany colony of the Cameroons exists in the shape of two aircraft captured by the British forces under the command of Lt.-Genl. Dobell on 11 December, 1914, at Bare.

These two aircraft (it became apparent afterwards that is was only one and a half) were offered to the Union Government on 16 December of that year by the Secretary for the Colonies and were gratefully accepted.

The aircraft were shipped to Cape Town on the Edna Woermann and on arrival dr. J. L.Weston was requested to assemble them.

Seen in the light of aviation after 1914-1915 dr. Weston's list of components is most interesting.

In 1919 the aircraft again became the subject of discussion. There were now sufficient components to build one complete aircraft.

It is impossible to ascertain from the available documentation whether this aircraft was ever exhibited at Salt River (March, 1919).

Approximately during this time the aircraft was offered to the South African Museum and accepted as a gift.

An enquiry made at the museum concerned brought to light that the aircraft is no longer in the museum. The editorial would like to know from interested readers whether they can provide information concerning the subsequent fate of the Taube aircraft from the German Cameroons.
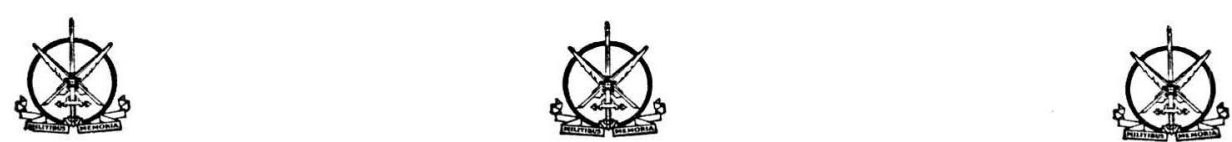


\section{AANTEKENINGE}

1 Die skeepsnaam is as Renate Amsinck of Renata Amsinck aangedui. Daar is o.m. sewe skroewe en drie dele van verkoelers, waarvan een beskadig, aangetref.

2 Aangaande die Taube-vliegtuig, 'n skepping van die Oosterrykers Igo Etrich en Franz Wells, kom. o.m. besonderhede in John R. Cuneo se publikasie Winged Mars, Harriburg, (PA, 1942), deel I, p. 33 e.v., voor. Die Duitse regte is deur E. Rumpler gekoop en aan die begin van 1910 is die aanvanklik populêre vliegtuig op Johannesburg getoets. Sketse kom voor op p. 92 van genoemde werk. M.b.t. die Jeannin is geen besonderhede aangetref nie.

3 Amptelike skrywe Direkteur Suid-Afrikaanse Museum - Senior Stafoffisier M.H.A.D., Kaapstad, 6.2.1970.

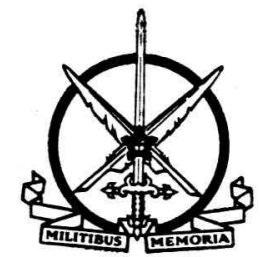

